\title{
High Speed Railway and Regional Coordinated Development —An Empirical Study on Beijing-Tianjin-Hebei Region
}

\author{
Xiuying Liu ${ }^{a^{*}}$, Xiaoyan Lin $^{a}$,Yuhui Zhou ${ }^{b}$ \\ ${ }^{a}$ School of Economics and Management, Beijing Jiaotong University, China \\ ${ }^{\mathrm{b}}$ School of Electrical Engineering, Beijing Jiaotong University, China \\ *Corresponding author: Xiuying Liu, e-mail address: liu_xiuying11@163.com
}

\begin{abstract}
The vast construction of High Speed Railway (HSR) is an important policy to improve the quality of transportation infrastructure in China. The influence of HSR on coordinated development of regional cities in Beijing-Tianjin-Hebei Region is investigated. The research shows that HSR has a positive effect on the economic growth of the city and benefits the tertiary industry development of the city, while the influence of HSR on population scale of cities is negative. In addition, the impact of HSR on economic promotion in big cities is more effective than in small cities. According to actual situation and empirical analysis, this could be attributed to the siphoning influence of population and economic resources from small cities to the big cities, which is caused by unbalanced regional development and exacerbated by HSR. HSR promotes the development of Beijing-Tianjin-Hebei cities economy while at the same time it further expands the development gap and lead to more uncoordinated development of regional cities.
\end{abstract}

Key words:regional coordinated development; HSR; Beijing-Tianjin-Hebei; DID

\section{Introduction}

China has the largest scale and fastest developing pace of High Speed Railway (HSR) in the world. According to the Statistics of International Union of Railways (UIC), in 2015, there are 15 countries regions operating HSR and the total mileage is over $30000 \mathrm{~km}^{1}$. China's HSR operating mileage is $16000 \mathrm{~km}$, more than half of the world's HSR total mileage. According to "the medium and long-term railway network planning "and" the 13th planning of railway network", China's HSR construction will continue to run at high pace. How China's HSR policy, which is to improve the quality of China's transportation infrastructure, will affect the urban economy and regional coordinated development?

Whether HSR will promote different urban economy growth and regional economic coordinated development is highly controversialin academic community. Some scholars study and find out transportation infrastructure is a key factor in promoting regional economic growth and development. The World Bank (2006) report deems that "one of the best ways to promote the development of underdeveloped regions, is to ensure that its cities has effective accessibility with growing and competitive market" ${ }^{2}$. Lin Xiaoyan et al. (2010) ${ }^{3}$ find that HSR will improve the existing transportation infrastructure, and then influence the spatial distribution of economic activities and the development of regional economy. Besides, Liu Binglian et al. (2010) ${ }^{4}$ and Ye Changyou et al. (2013) ${ }^{5}$ agree that transportation infrastructure has a positive promoting effect on economic growth and have a common logic: transportation infrastructure is an important way for a city or a region to blend into the market, access to the 
welfare of market and technology. Also, it is a market links to connect basic economic resources of production, which is essential to regional economic development.

However, some scholars think that transportation infrastructure is not always promoting the development of regional economy.In contrast, it may become a handicap. Fogel(1964) puts forward a famous point of viewin his book "the railway and U.S. economic growth", namely "unless the needs of the development of the region economy, transportation infrastructure itself does not have much effect". Rietveld(1995) ${ }^{6}$, Wang Yao et al. (2014) ${ }^{7}$ and Lin Xiaoyan et al.(2015) ${ }^{8}$ all state that transportation can play a positive role only in appropriate area at appropriate time.

Although economists hold different opinions on whether transportation infrastructure such as high-speed railway will bring the regional economy growth and regional economic coordinated development. However,it is indisputable that convenient transportation will improve accessibility, reduce transportation cost and increase flow of other factors. This paper selects the panel data of Beijing-Tianjin-Hebei region, using fixed effect evaluation model Differences-In-Differences (DID) to estimate the effect of HSR on the city's economic development in Beijing-Tianjin-Hebei region. Results show that HSR facilitate the development of city's economy while leading to uncoordinated development of regional cities.

\section{Integration in Beijing-Tianjin-Hebei region and model design}

\subsection{Integration in Beijing-Tianjin-Hebei region}

Integrated development in Beijing-Tianjin-Hebei region has a long history, especially integrated transportation gets rapid developed. Since Beijing-Tianjin inter-city high-speed railway operated in 2008, HSR has developed rapidly in Beijing-Tianjin-Hebei region.By the end of 2013, the "G" and "C" HSR coverage is 53.85\%, the whole HSR coverage is $61.54 \%$. However, the economic coordinated development in Beijing-Tianjin-Hebei is not so smooth. The big cities develop rapidly while small and medium-sized cities develop much slower, widening the development gap. Besides, industrial distribution is not reasonable, human resources and other economic elements tend to flow to the big cities. HSR in Beijing-TianjinHebei region is an essential part of the integration of the transportation network. The role of HSR in regional economic growth and regional economic integration is worth in-depth study.

\subsection{Econometric model: Differences-In-Differences (DID)}

China's massive HSR construction was considered as a policy.We employ a two-period DID modelto evaluate the effect of city economic development with and without HSR in the region, so as to give relatively robust conclusions. The sample was divided into control group and experimental group, among them, the control group contain the cities without HSR link in 2008 and 2013; the experimental group contain the cities with HSR link in 2008 and 2013. We examine the influence of economic development from the spatial dimension (with or without HSR cities) and time dimension (before and after HSR operating). The basic mode is as follow:

$$
\log N_{i t}=\beta_{0}+\beta_{1} \text { connect }_{i t}+\beta_{2} y_{i t}+\beta_{3} y_{i t} \times \text { connect }_{i t}+\alpha_{i}+\varepsilon_{i t}
$$


The dependent variable $N_{i t}$ repesents the scale of the population (or the per capita GDP growth rate, or the secondary/tertiary industry location quotient) in $i$ city and in $t$ period. The independent variable connect $_{i t}$ is regional virtual variables, on behalf of the regional effect, without HSR assign 0, with HSR assign 1; $y_{i t}$ is virtual variables of time, the year 2008 assign 0 , the year 2013 assign $1 ; y_{i t} \times$ connect $_{i t}$ represent HSR effect; $\alpha_{i}$ is fixed effects of $i$ city, which is an unique and can be estimated parameter to each city, and will not be changed over time. $\alpha_{i}$ can effectively avoid the problem caused by omitted variables, and the fixed effects will be "difference" in the process of differencing.

According to the basic meaning of DID model: coefficient $\beta_{1}$ measures the time effects on dependent variables; $\beta_{2}$ measures regional effects, which has nothing to do with HSR; $\beta_{3}$ measures the HSR effect on regional development level of dependent variables,which is the focus study in this empirical research. In order to accurately measure the HSR impact on regional economic development, need to control other heterogeneity observed variables. Therefore, on the basis of the model (I), we add a series of control variables $X_{i j t}$ to control some basic factors of the economic development. Model equation is as follow:

$$
\log N_{i t}=\beta_{0}+\beta_{1} \text { connect }_{i t}+\beta_{2} y_{i t}+\beta_{3} y_{i t} \times \text { connect }_{i t}+\sum_{j=1}^{n} \gamma_{j} X_{i j t}+\alpha_{i}+\varepsilon_{i t}
$$

For the selection of control variables $X_{i j t}$, we refer to the Steven N. Durlauf et al. (2004) ${ }^{9}$ to summarize the influential factors of economic growth. Control variables contain three parts: basic elements variables, which include the capital (investment in fixed assets) and the effective labour (staff number accounts for the proportion of total population); traffic factors, railway freight volume and railway passenger volume; other control variables, the industrial structure and fiscal expenditure related to the level of economic development. 13 cities in Beijing-Tianjin-Hebei region are the analysis object. All the data comes from "China City Statistical Yearbook" (2009 -2014).

\section{The empirical results analysis}

\subsection{Impact on the urban population}

Equation (II) can be formed as different equations by changing different dependent variables and adding different control variables. Equations (1) - (5) are the regression results of theHSR effect on city population (shown in Table 1). After adding the control variable, the estimated HSR effect coefficients are negative, indicating that HSR effect is more likely to reduce the size of the urban population. This may be a siphoning effect on urban population of the surrounding small cities through HSR. For urban population size, regional effects and time effects are positive, and the statistical results were more than $10 \%$ on the level of statistical significant. The coefficients of investment in fixed assets and rail passenger volume are notably positive and statistically significant,which indicates that investment in fixed assets and rail passenger traffic can positively affect urban population size. The coefficients of effective labour factor are negative and statistically significant. Statistical results of other variables are not significant. 
Table 1 - The regression results of the HSR effect on city population

\begin{tabular}{|l|c|c|c|c|c|}
\hline Variables & $(1)$ & $(2)$ & $(3)$ & $(4)$ & $(5)$ \\
\hline connect & $0.321^{* *}(2.015)$ & $0.189^{* *}(1.915)$ & $0.302^{* * *}(2.567)$ & $0.220^{* *}(1.874)$ & $0.162^{*}(1.546)$ \\
\hline $\mathrm{y}$ & $-0.192^{*}(-1.483)$ & $-0.305^{* * *}(-3.677)$ & $-0.177^{* *}(-1.871)$ & $-0260^{* * *}(-2.770)$ & $-0.295^{* * *}(-3.321)$ \\
\hline $\mathrm{y} \times$ connect & $0.067(0.367)$ & $-0.019(-0.173)$ & $0.018(0.135)$ & $-0.014(-0.099)$ & $-0.033(-0.318)$ \\
\hline fix & & $0.521^{* * *}(4.933)$ & & & $0.451^{* * *}(3.141)$ \\
\hline EffLab & & $-0.222(-0.604)$ & & & $-1.281^{* *}(-1.838)$ \\
\hline freight & & & $0.057(0.679)$ & & $-0.098^{*}(-1.333)$ \\
\hline PasTraf & & & $0.279^{* * *}(3.530)$ & & $0.324^{* * *}(3.078)$ \\
\hline fiscal & & & & $0.366^{* * *}(4.774)$ & $0.045(0.180)$ \\
\hline MSR & & & & $0.146(1.255)$ & $0.074(0.744)$ \\
\hline constant & $2.808^{* * *}(50.218)$ & $-0.727(-1.047)$ & $1.857^{* * *}(7.779)$ & $0.459(0.938)$ & $-1.056(-1.167)$ \\
\hline R2 & 0.324 & 0.779 & 0.674 & 0.687 & 0.871 \\
\hline R2_A & 0.232 & 0.724 & 0.592 & 0.609 & 0.798 \\
\hline
\end{tabular}

Note: (1) The values in brackets are t statistics; (2)***、**、*meanthe estimated values are in 1\%, 5\%, 10\% level statistically significant respectively, and the same applies to the following tables.

\subsection{Impact on per capita GDP growth rate}

Table 2 shows the regression results of HSR effecton per capita GDP growth rate.The estimated coefficients of HSR effect are positive, indicating that HSR is beneficial to the improvement of the urban per capita GDP growth rate. HSR expands the size of the market, thereby enabling the city to enjoy the benefits related to economies of scale, and contribute to economic growth as well as per capita GDP growth rate. Time effects and regional effects are negative, which is in step with the overall trend of China's economic growth in this period. Effective labour estimated coefficients are significantly positive, indicating that effective workimprove the level of per capita GDP growth rates. Railway freight and railway passenger traffic estimated effect are negative, and the results arestatisticallyinsignificant. The estimated effect of fiscal expenditure and industrial structure are positive, while the estimated results of investment in fixed assets are not significant.

Table 2 - The regression results of the HSR effect on the growth rate of GDP per capita

\begin{tabular}{|l|c|c|c|c|c|}
\hline Variables & $(6)$ & $(7)$ & $(8)$ & $(9)$ & $(10)$ \\
\hline connect & $-0.430(-0.875)$ & $-0.381(-0.731)$ & $-0.491(-0.955)$ & $-0.551(-1.058)$ & $-0.939^{*}(-1.437)$ \\
\hline $\mathrm{y}$ & $-0.892^{* *}(-2.240)$ & $-0.794^{* *}(-1.813)$ & $-0.857^{* *}(-2.070)$ & $-0.966^{* * *}(-2.319)$ & $-1.271^{* *}(-2.294)$ \\
\hline $\mathrm{y} \times$ connect & $0.029(0.051)$ & $-0.004(-0.007)$ & $0.027(0.046)$ & $0.079(0.130)$ & $0.207(0.316)$ \\
\hline fix & & $-0.235(-0.423)$ & & & $-0.841(-0.937)$ \\
\hline EffLab & & $1.788(0.924)$ & & & $1.413(-0.325)$ \\
\hline freight & & & $-0.288(-0.779)$ & & $-0.379(-0.822)$ \\
\hline PasTraf & & & $0.170(0.490)$ & & $-0.809(-1.229)$ \\
\hline fiscal & & & & $0.266(0.781)$ & $2.263^{*}(1.439)$ \\
\hline MSR & & & & $-0.213(-0.414)$ & $0.015(0.025)$ \\
\hline constant & $1.245^{* * *}(7.215)$ & $2.655(0.726)$ & $1.660^{*}(1.589)$ & $-0.251(-0.116)$ & $-3.396(-0.601)$ \\
\hline R2 & 0.511 & 0.534 & 0.526 & 0.532 & 0.617 \\
\hline R2_A & 0.445 & 0.637 & 0.407 & 0.415 & 0.401 \\
\hline
\end{tabular}




\subsection{Impact on the secondary and the tertiary industry}

Table 3 and table 4 show the regression results of HSR effect on the secondary and the tertiary industry respectively. HSR effect on the secondary industry location quotient plus or minus changed and statistically insignificant, which means HSR effect on the secondary industry location quotient is uncertain. HSR effect on the tertiary industry location quotient is positive and some of them statistically significant, indicating that HSR effect on the tertiary industry location quotient is positive and HSR benefit the development of urban tertiary industry. The effect estimated coefficients of fixed asset investment on the secondary industry location quotient aresignificant positive, while on the tertiary industry aresignificant negative, indicating that fixedasset investment promote the development of secondary industry but has relative negative effects on tertiary industry development. It is possibly relative with the reality that a large proportion of investment in fixed assets investment in the secondary industry. Effects of other control variables are in line with expectations. The control variables play an important role to correctly estimate the effects of HSR.

Table 3 - The regression results of the HSR effect on secondary industry location quotient

\begin{tabular}{|l|c|c|c|c|c|}
\hline Variables & $(11)$ & $(12)$ & $(13)$ & $(14)$ & $(15)$ \\
\hline connect & $-0.023(-0.139)$ & $-0.099(-0.923)$ & $0.042(0.334)$ & $0.125(1.139)$ & $-0.010(-0.096)$ \\
\hline $\mathrm{y}$ & $0.040(0.302)$ & $-0.097(-1.076)$ & $0.000(0.003)$ & $-0.126^{*}(1.440)$ & $-0.023(-0.252)$ \\
\hline $\mathrm{y}^{\times}$connect & $0.002(0.011)$ & $0.036(0.299)$ & $0.045(0.317)$ & $-0.134(-1.045)$ & $-0.087(-0.803)$ \\
\hline fix & & $0.351^{* * *}(3.064)$ & & & $0.334^{* *}(2.237)$ \\
\hline EffLab & & $-2.311^{* * *}(-5.806)$ & & & $-1.066^{*}(-1.474)$ \\
\hline freight & & & $0.181^{* *}(2.022)$ & & $-0.015(-0.190)$ \\
\hline PasTraf & & & $-0.370^{* * *}(-4.411)$ & & $-0.150^{*}(-1.370)$ \\
\hline fiscal & & & & $-0.239^{* * *}(-3.346)$ & $-0.097(-0.372)$ \\
\hline MSR & & & & $0.459^{* * *}(4.232)$ & $0.313^{* * *}(3.016)$ \\
\hline constant & $1.060^{* * *}(18.276)$ & $-1.082^{*}(-1.438)$ & $1.529^{* * *}(6.035)$ & $2.234^{* * *}(4.891)$ & $-0.247(-0.263)$ \\
\hline R2 & 0.007 & 0.645 & 0.498 & 0.627 & 0.809 \\
\hline R2_A & -0.129 & 0.556 & 0.373 & 0.534 & 0.702 \\
\hline
\end{tabular}

Table 4 - The regression results of the HSR effect on tertiary industry location quotient

\begin{tabular}{|l|c|c|c|c|c|}
\hline Variables & $(16)$ & $(17)$ & $(18)$ & $(19)$ & $(20)$ \\
\hline connect & $0.034(0.157)$ & $0.082(0.850)$ & $-0.044(-0.309)$ & $-0.194^{*}(-1.688)$ & $-0.041(-0.386)$ \\
\hline $\mathrm{y}$ & $-0.025(-0.139)$ & $0.115^{*}(1.428)$ & $0.025(0.219)$ & $0.164^{* *}(-1.780)$ & $0.004(0.049)$ \\
\hline $\mathrm{y} \times$ connect & $0.121(0.477)$ & $0.036(0.330)$ & $0.050(0.307)$ & $0.217^{*}(1.609)$ & $0.157^{*}(1.480)$ \\
\hline fix & & $-0.257^{* * *}(-2.504)$ & & & $-0.373^{* * *}(-2.566)$ \\
\hline EffLab & & $3.102^{* * *}(8.683)$ & & & $1.636^{* *}(2.319)$ \\
\hline freight & & & $-0.161^{*}(-1.580)$ & & $0.007(0.097)$ \\
\hline PasTraf & & & $0.535^{* * *}(5.620)$ & & $0.051(0.474)$ \\
\hline fiscal & & & & $0.503^{* * *}(6.697)$ & $0.369^{*}(1.448)$ \\
\hline MSR & & & & $-0.408^{* * *}(-3.582)$ & $-0.227^{* *}(-2.244)$ \\
\hline constant & $0.802^{* * *}(10.428)$ & $2.217^{* * *}(3.281)$ & $-0.186(-0.649)$ & $-2.032^{* * *}(-4.233)$ & $0.884(0.964)$ \\
\hline R2 & 0.058 & 0.846 & 0.653 & 0.778 & 0.902 \\
\hline R2_A & -0.070 & 0.808 & 0.566 & 0.723 & 0.847 \\
\hline
\end{tabular}




\section{Conclusions}

The influence of HSR on coordinated development of regional cities in Beijing-Tianjin-Hebei Region is investigated and analyzed by employing Differences-In-Differences (DID), a policy estimation model. The biggest policy implication of the study is to empirically clarify thatthe impact of HSR on economic promotion in big cities is more effective than in small cities. This could be attributed to the siphoning influence of population and economic resources from small cities to the big cities, which is caused by unbalanced regional development and exacerbated by HSR, namely the siphoning effect passage role of HSR. The basic function of transportation is to conveniently access to the labour, logistics, capital information, technology between cities. Improved transportation infrastructure can effectively reduce transportation costs, increase factors mobility and improve regional accessibility. However, the direction and quantity of elements between regional cities are very different, leading to different effects of transportation in various areas with different levels of economic development. For specific regions, it is a more complex and more significant subject to further explore how far and what level transportation infrastructure influence different cities in a region, which is the direction of future research.

\section{Acknowledgements}

The authors seriously thank the financial support from National social science fund project (15BTJ003) and Research Center for Beijing Transportation Development project (ZSJT 201503).

\section{References}

1. UIC. HIGH SPEED RAIL HISTORY [EB/OL]. 2015-07-24. http://uic.org.

2. Word Bank. World Development Report 2006 [R] Beijing: Tsinghua university press.

3. X.Y.Lin, X.J.Chen, Y.F.Bai, X.M.Han, Quantitative analysis of the beijing-tianjinintercity high-speed railway impact on regional economic [J]. Railway Economics Research, 2010(5): 5-11.

4. B.L.Liu, P. Wu, Y.H. Liu, Transportation Infrastructure and the Increase in TFP in China----Spatial Econometric Analysis on Provincial Panel Data [J].China Industrial Economics, 2010 (3): 54-64.

5. C.Y.Ye, X.J. Wang, Transport Infrastructure and Economic Growth in China--Based on Spatial Econometrics of Panel Data with Provincial Data [J].Industrial Economics Research,2013 (2) : 40-47.

6. Piet. Rietveld, Infrastructure and spatial economic development [J]. The Annals of Regional Science, 1995(29): 117-119.

7. Y.Wang, M.Nian, Did High-speed trains promote the development of regional economy? [J]. Shanghai Economic Research, 2014 (2): 82-91.

8. X.Y.Lin, S.Luo, Z.H.Zhu, Relationship between Regional Quality and HSR Social Utility:A Study on How to Choose Construction Opportunity of HSR. [J]. China Soft Science,2015(4): 76-85.

9. S.N.Durlauf, P.A.Johnson and R.W.J. Temple, Growth econometrics. In: P. Aghion and S. Durlauf (eds.), Handbook of Economic Growth, 2004(1A). North-Holland: Amsterdam, pp. 555-677. 